\title{
From the Evidence of Violence Against Children to a Prevention-Oriented Response in Malawi: Planning for Social Services with a Public Health Model for Social Work Engagement
}

\author{
Brendan Ross $^{1} \cdot$ Karen Smith Rotabi $^{2} \cdot$ Nankali Maksud $^{2}$
}

Published online: 4 September 2015

(C) Springer International Publishing 2015

\begin{abstract}
Globally, violence has long been considered a serious and persistent social problem that is often presented as a public health concern. In the past decade, violence has received greater attention in terms of social interventions, especially using a public health model of social programming. A recent survey on violence against children is presented, using Malawi as a case example. This evidence is applied to a primary, secondary, and tertiary prevention framework for programming, with an orientation to social worker as leader in social policy, social intervention planning, and service delivery. Four opportunities for engagement are presented: (1) community building, (2) early identification of violence, (3) social casework with a strong aftercare approach, and (4) program development. Training of the social service workforce is finally considered, with recommendations for core professional skill areas for learning and capacity building.
\end{abstract}

Keywords Prevention · Violence against children · Social services $\cdot$ Evidence $\cdot$ Social planning $\cdot$ Social work

Globally, violence has long been considered a serious and persistent social problem that is often presented as a public health concern (Bulhan 1990; Centers for Disease Control and Prevention n.d.; Dahlberg \& Krug 2002; Hammond et al. 2006; Rippe 2011). In the past decade, violence has received greater attention in terms of social interventions as a result, in part, of the World Health Organization's (WHO) World Report

Karen Smith Rotabi

ksrotabi@yahoo.com

UNICEF, Lilongwe, Malawi

2 Department of Social Work, United Arab Emirates University, Al Ain, United Arab Emirates on Violence and Health (Krug et al. 2002; Mian 2004). Recently, the topic has been gaining renewed attention from policy makers as evidenced by the Sixty-Seventh World Health Assembly (2014) when a historic resolution was adopted addressing the role of the health system in preventing violence against women and children.

This resolution acknowledges that violence persists globally and that it must be addressed systematically with a strong emphasis on early intervention with children and adolescents (Sixty-Seventh WHA 2014). Focusing on childhood interventions is particularly important for breaking the cycle that violence against children (VAC) creates. As the WHA noted:

Preventing interpersonal violence against children can contribute significantly to preventing violence against women and girls and children, that being abused and neglected during infancy and childhood makes it more likely that people will grow up to perpetrate violence against women, maltreat their own children, and engage in youth violence... (2014, p. 2).

The WHO has prioritized global responses to violence, and the WHA has called for a "comprehensive and multisectoral response" (p. 2). It was also argued that there is a "need to scale up interpersonal prevention policies and programmes to which the health system contributes and that while some evidence-based guidance exists on effective interventions, more research and valuation of these and other interventions is required" $(2014$, p. 3$)$. The WHO is now developing a global plan of action to strengthen health systems to respond to interpersonal violence across the continuum of care, including prevention (Sixty-Seventh WHA 2014). A number of advocacy groups and development organizations, including the African Child Policy Forum (2014) and the United Nation's Children's Fund (UNICEF) have made commitments to 
addressing VAC which is defined broadly to include interpersonal violence between youth (UNICEF 2014).

\section{The Role of Social Work in Responding to This Call to Action}

As planning commences, it is important to recognize that those charged with organizing public health prevention approaches often underestimate the important role that social workers have in responding to an array of health and social problems, including violence. The social worker should be seen as a critical actor in the public health approach that encompasses surveillance of the problem, identifying risk and protective factors, responding with comprehensive plans, and developing systems of care across the continuum of primary, secondary, and tertiary prevention (Bloom 2008).

In fact, public health interventions and community capacity building anchor are the earliest conceptions of social work, notably the neighborhood work carried out by Jane Addams and others committed to a holistic approach to social care, child protection, and family support (Farrell 1967; Levine \& Levine 1992). Even with the development of evidence-based interventions addressing societal and family-based violence (McLennen 2010), the role of social workers and social service professionals is often underestimated by policy makers. Social workers can be effective change agents across the prevention continuum. However, there are many missed opportunities to incorporate the profession's expertise in social planning, advocacy, community building, social casework, psychosocial education, and trauma counseling.

Evidence-based interventions to prevent violence and support families frequently involve social workers. For example, a classic intervention is parenting skills programs based on sound evidence with curriculum focusing on child development knowledge and skill-building, including effective communication and appropriate discipline strategies (Kaminski et al. 2008; WHO 2009b). At the community level, social workers have supported activities to address violence in schools (Merrell et al. 2008) and communities, including community building with an orientation to strengths and protective strategies (Catalano et al. 2009). Social workers have also been involved in innovative programs to facilitate peer based psychosocial support for survivors of violence to include the provision of life skills education in assertiveness, conflict avoidance, self-defense, and effective communication (Sarnquist, et al. 2014). These are just a few of the evidencebased social interventions in which families and youth are empowered with education and training to prevent violence against children (WHO 2009b).

It is important to point out that the evidence base for effective violence programming in low-income countries is weak (Ellsberg et al. 2015). However, in a comparison study on the efficacy of various violence prevention interventions identifies a core feature of successful interventions - the engagement of multiple stakeholders as agents of change (Ellsberg et al. 2015). This particular finding has important ramifications for intervention planning and should place a renewed emphasis on the function of the social worker as facilitator and skilled guide in collaborative initiatives - the professional capacity to facilitate collaborative approaches for systematic change is a clear strength of the discipline (Sowers \& Rowe 2006). In fact, the social worker is the only professional who has a function across the continuum of care with a broad array of skills oriented towards not only mental health treatment for children and families (Stardt 2008) but also community building, systems of care building, and access to justice within an advocacy framework (Gamble \& Weil 2008).

In this time of renewed awareness about violence and the WHA's charge to address the problems, social work, as a discipline, can provide leadership on a variety of VAC interventions in which the social worker is a key or allied professional. In conjunction with the global push towards promoting child rights and responding to VAC, the further professionalization of social work and other social service providers in developing countries is critical (Mónico \& Rotabi 2014). This is an especially important consideration in low-resource settings where violence prevalence rates are high and service delivery is low. The purpose of this article is to build upon the evidence of Malawi's recently released 2014 Violence Against Children and Young People Survey (henceforth simply called VACS or 'the survey') to identify workforce development opportunities that can strengthen the social welfare workforce, thereby improving the capacity of social workers to effectively respond to VAC in Malawi (Ministry of Gender, Children, Disability and Social Welfare of the Republic of Malawi, United Nations Children's Fund, The Center for Social Research at the University of Malawi, and the Centers for Disease Control and Prevention 2014).

Malawi is presented as a case example, integrating recent research evidence on the problem; it is presented because the authors have been highly engaged in child protection planning work there, within the development sector, and their involvement as change agents is informed by evidence on VAC. Furthermore, this Sub-Saharan African nation provides a particularly illustrative case because the VAC evidence presented in this paper is new knowledge - very recently released research results - and data inform the planning and programming to address VAC (Ministry of Gender, Children, Disability and Social Welfare of the Republic of Malawi et al. 2014) from a public health approach incorporating primary, secondary, and tertiary interventions.

Critical to the process of social intervention to address VAC in Malawi is workforce planning. Once prevention interventions are explored, this article then identifies opportunities to strengthen social services, emphasizing the need to 
build upon the existing capacities of social workers and social care interventions. A prevention framework guides the discussion as a way of thinking about systems transformation that moves beyond a crude "band aid" approach. This reactionary system has thus far prioritized clinical and legal responses to extreme violence, usually rape, and movement forward must incorporate early identification and referral interventions across the range of VAC. Workforce recommendations, including training of social service professionals, are provided in the discussion to effectively address VAC in Malawi and ultimately transform systems of care through social planning based on evidence.

\section{Violence Against Children in Malawi: Background and the Evidence}

Malawi is a country of 15 million people with children and youths below the age of 15 constituting $46 \%$ of the population (Population Reference Bureau n.d.). Malawi's social and health problems are similar to other Sub-Saharan nations: HIV/AIDS is occurring at epidemic rates, malaria is prevalent, malnutrition is a top cause of death for children, child marriage is occurring at one of the highest rates in the world, and societal and familial violence is endemic (Human Rights Watch 2014; Rowan 2014; WHO 2015). Poverty exacerbates many of the underlying conditions and behaviors of violence, while limited resources impact effective responses (Baatsen et al. 2014). Risk factors include family disintegration, domestic violence, substance abuse, mental health problems, disability, and social norms that promote violence (Bulhan 1990; Centers for Disease Control and Prevention n.d.; Dahlberg \& Krug 2002; Larkin et al. 2014; Moss 2013).

The VACS findings recently released in Malawi provide the most comprehensive research data on the problem ever produced (Ministry of Gender, Children, Disability and Social Welfare of the Republic of Malawi et al. 2014). Survey data were collected by the University of Malawi Centre for Social Research in 2013 for the Ministry of Gender, Children, Disability and Social Welfare with technical support from UNICEF and the U.S. Centers for Disease Control (CDC). Results are based on a representative sample of children ages $13-17^{1}$ years, in addition to young adults ages $18-24 .^{2}$ Surveys were administered throughout the country, and findings are generalizable with statistical analysis being carried out by the CDC. Measures for VAC were based on sexual violence, physical violence, and emotional violence as discussed next.

\footnotetext{
${ }^{1} 13-17$ year olds were asked questions about violence in the previous 12 months and age at first incident.

${ }^{2} 18-24$ year olds were asked about violence that occurred prior to the age of 18. Data from this particular age group are presented unless otherwise stated.
}

\section{VACS Definition of Sexual, Physical, and Emotional Violence and Evidence}

When developing the VACS questionnaire domains, definitions of violence against children were developed and survey questions are reflective of the concepts (Ministry of Gender, Children, Disability and Social Welfare of the Republic of Malawi et al. 2014). A summary of definitions is presented below, and they incorporate both interfamilial violence as well as societal violence that include interpersonal violence among youth (e.g., bullying, gang behavior, and other manifestations of juvenile violence).

Sexual violence is defined as including all forms of sexual abuse and exploitation of children. It encompasses a range of offenses, including unwanted attempted sex and rape. Within a continuum of sexual violence, a child may experience attempts at nonconsensual sex acts or abusive sexual contact, such as touching, and there may be noncontact sexual abuse that includes harassment and threats of sexual violence. Exposing children to prostitution, pornography, or other unlawful sexual practices is also included in this definition. It is important to underscore that force and coercion are key to sexual violence against children, regardless of the setting or relationship between the child and perpetrator. Sexual violence takes place in all settings, most frequently in homes but also in the child's neighborhood and school setting (Ministry of Gender, Children, Disability and Social Welfare of the Republic of Malawi et al. 2014).

Physical violence is defined as including all forms of physical abuse of children. This includes punching, kicking, whipping, beating with an object, choking, smothering, trying to drown, burning intentionally, or using/threating to use a weapon such as a knife or gun. Physical violence takes place in both the home and greater society, most especially school settings or during passage to school where children may assault each other or when educators may use excessive force and corporal punishment (Ministry of Gender, Children, Disability and Social Welfare of the Republic of Malawi et al. 2014).

Emotional violence is defined as including all forms of verbal abuse and other acts such as dismissing a child's basic psychological needs for comfort and support. It encompasses a range of offenses, including a child being ridiculed or put down, being told that they are not loved or are undeserving of love, and being told that the parent or guardian wishes that the child was never born. It should be noted that emotional violence often cooccurs with physical and sexual violence; that is, a child is verbally abused simultaneously with physical violence or they are threatened as a part of sexual violence (Ministry of Gender, Children, Disability and Social Welfare of the Republic of Malawi et al. 2014). Like the other forms of violence, emotional violence takes place in homes as well as the greater society.

Because the above definitions are integrative of both family and societal violence, including interpersonal violence among juveniles (Ministry of Gender, Children, Disability and Social Welfare of the Republic of Malawi et al. 2014), all types of 
violence in all settings are areas of inquiry in VACS. The survey also identified the perpetrators of violence, the location of violence, the time that the violence occurred, the disclosure rates and identity of persons to whom survivors of violence disclose, survivor access to services, longer term health consequences of violence, and HIV testing behavior (Ministry of Gender, Children, Disability and Social Welfare of the Republic of Malawi et al. 2014).

Results from the VACS indicate that nearly two thirds of children (more than 5 million total) suffered abuse prior to 18 , illustrating that epidemic levels of violence are perpetrated against children and youth in Malawi. More than half of all Malawians ages 18-24 have witnessed physical violence in the home prior to the age of 18 . One in three of these 18-24 year olds also witnessed violence in the community. Two out of three children are victims of some form of violence during their childhood. If a child experiences violence once, she/he is likely to have repeated experiences throughout childhood. Specific findings, as related to the three types of abuse, are as follows.

\section{Sexual Violence Evidence}

The VACS findings indicate that girls experience greater levels of sexual violence than boys; $22 \%$ of girls and $15 \%$ of boys suffer sexual abuse. The average age at the first incident of sexual violence was 14.3 years for girls and 13.9 years for boys. Nearly $50 \%$ of perpetrators who abuse girls were perceived to be at least 5 years older than the victim. The most frequent location of sexual abuse for girls was in the home or on the road while boys were more likely to be abused in their own home or at school. Of those experiencing sexual abuse, $68 \%$ of girls and $74 \%$ of boys experienced multiple incidences across their childhood. More than half of boys and girls told someone about the sexual abuse, usually a friend. However, less than $10 \%$ actually received professional help. Moreover, less than a quarter of girls aged 13-17 knew of a place to seek help for sexual violence.

\section{Physical Violence Evidence}

The VACS results indicate that boys experience greater levels of physical violence than girls with $65 \%$ of boys and $42 \%$ of girls suffering abuse. The first incident of physical violence, in more than half of the reported cases occurred between 6 and 11 years of age. The majority of children who report physical violence have multiple incidences across their childhood, $79 \%$ for girl survivors and $88 \%$ for boy survivors. VACS also found that girls are more likely to be physically abused by a woman in the family (mother and stepmothers), whereas boys were at high risk of being abused by their peers. More than half of 1317 year olds told someone about physical violence, usually a relative. Yet, only $11 \%$ of girls and $6 \%$ of boys ever received services. Importantly, the most common reason for not seeking help for physical violence was that the survivor did not think it was a problem - they perceived the incident was their fault or that it was normal behavior. Girls are more likely than boys to report, seek, and receive services to respond to physical violence.

\section{Emotional Violence Evidence}

According to the VACS, boys experience greater levels of emotional violence than girls with $29 \%$ of boys and $20 \%$ of girls enduring emotional abuse. Of these children, approximately $85 \%$ bear multiple incidents of emotional violence during their childhood. Age at first experience of emotional abuse was most often 12-17 years for girls and 6-11 years for boys. It should be noted that emotional violence often occurs simultaneously with physical and sexual violence.

The long-term impact of VAC is decreased self-esteem for survivors and, in the worst cases, depression as well as other mental health problems (Mian 2004; UNICEF 2014; White \& Widom 2003). Also, because violence is a learned behavior, these children are more likely to abuse themselves as well as their partners and future children. Also, substance abuse is not uncommon among survivors (Centers for Disease Control \& Prevention, n.d.; UNICEF 2014; White \& Widom 2003). In sum, the emotional toll is significant and VAC ultimately underlies many social problems; often, the term "cycle of violence" is used to capture the perpetual nature of survivor eventually becoming perpetrator (Widom 1989). While not all survivors go on to abuse later, the cyclical nature of the problem is important to underscore.

\section{Qualitative Evidence on Violence Against Children in Malawi}

Qualitative research carried out in Malawi with children and youths (ages 13-17 years) indicates underlying factors of violence in four areas: increasing incidence of orphanhood, high incidence of poverty, traditional and cultural practices, and lack of protection for vulnerable children (Makoka 2014). Findings included the observation that corporal punishment of children is a cultural expectation of parenting and physical violence is frequently coupled with verbal abuse. School-level violence findings indicated that classrooms are common locations of aggression by teachers and peers, including harsh physical punishment (Makoka 2014). Greater communitylevel violence was reported to be, in part, associated with substance abuse as children reported being abused physically and verbally by those who were intoxicated and that violence often takes place in adult entertainment locations (e.g., bars and community events) (Makoka 2014).

Sexual abuse was the most common form of violence reported by children and youths in this study (Makoka 2014). 
Meanwhile, perpetrators were reported to most commonly be either significantly older people or peers. The view that girls brought rape upon themselves because of the way they dressed and/or their involvement in community entertainment during nighttime hours was commonly held (Makoka 2014). This false belief that girls bring about or entice their own sexual assault is not uncommon globally (Sarnquist et al. 2014).

\section{Gender As an Important Consideration}

\section{Girls and Early Marriage: Unique Concerns}

Another reported underlying dynamic for rape was the incidence of girls being forced by their parents to engage in sexual relationships with older men (Makoka 2014). This parental behavior was often linked to the perpetrator's perceived wealth. This concern is further confirmed in a study on early marriage in 2014. Human Rights Watch (HRW) found that Malawi has one of the highest rates of prevalence of early marriage for girls in the world. Early marriage is that which takes place before the age of 18, and Human Rights Watch (2014) estimates that a significant number of girls are married before the age of 10 in Malawi. This social practice is often called "child marriage" or "child brides" and is linked to a variety of negative causes and consequences including school drop out for girls (Rowan 2009) and family and societal violence.

The VACS (Ministry of Gender, Children, Disability and Social Welfare of the Republic of Malawi et al. 2014) findings identified that child marriage (both formal and marriage-like relationships) occurred for $27 \%$ of female respondents, equating to approximately 1.25 million girls in Malawi. Remarkably, girls in these circumstances had a $50 \%$ increased risk of all forms of violence. Although sexual and emotional abuse are obvious forms of violence for child brides (HRW 2014), alarmingly, the VACS found that these girls also experience heightened rates of physical violence with the majority reporting such abuse, with the husband/partner as the perpetrator. These girls are exceptionally vulnerable to a wide array of social and health problems, including increased prevalence of depression and self-harm (HRW 2014). However, the VACS (Ministry of Gender, Children, Disability and Social Welfare of the Republic of Malawi et al. 2014) found that child brides often do not see violence as a serious problem and do not typically seek social services. Rather, violence appears to be a social expectation. This expectation and the prevalence of child marriage underscore dangerous gender-related social norms in Malawi (HRW 2014).

Consistent with the VACS, HRW (2014) found that early marriage practices exist throughout Malawi in both urban and rural areas. Economic hardships frequently underlie early marriage, (Rowan 2009) as the dowry is often an important social force in a parent's arrangement of early marriage. Moreover, it was identified that girls who are treated poorly in their home life, including VAC, are more likely to marry young. Furthermore, pregnancy during adolescence was reported to be a strong driver of early marriage. The stigma of unwed pregnancy and the resulting dishonor brought upon the family were also identified as catalysts for forced marriage of adolescents (HRW 2014; Makoka 2014).

Peer pressure was reported to encourage early marriage as some youths viewed it as prestigious. For some girls, wedlock also represents the opportunity to leave home and begin adulthood (Makoka 2014; HRW 2014). As a result of these interwoven dynamics, intervention in child marriage must be tailored to respond to social norms and address the unique pressures on girls to cut their childhood years short and enter into the obligations of adulthood early by undertaking the role of wife and mother.

\section{Boys and Physical Violence: Unique Concerns}

Differences in gender experience of childhood violence were detailed in the Sixty-Seventh WHA (2014). It was specifically noted that boys "are among those most affected by interpersonal violence, which contributes greatly to the global burden of premature death, injury and disability" and "has a serious and long-lasting impact on a person's psychological and social functioning" (p. 2). Evidence from the VACS further suggests that boys are likely to suffer violence at the societal level, such as abuse by their peers or violence at school. Frequently, boys are expected to begin work as soon as they are physically able to work in hard labor, often cutting short their education and emotional maturing process (Rowan 2009). Just as child marriage interventions must be tailored to respond to social norms related to gender and discrimination against girls, social norms promoting traditional ideas of male masculinity must also be effectively countered to prevent violence.

\section{Protecting Childhood in Malawi}

Child rights are anchored upon the belief that children are afforded special care and protection until they are 18 years old, as identified in the United Nations Convention on the Rights of the Child (Sowers \& Rowe 2006). However, in Malawi, the experience of childhood is truncated and children often find themselves pushed into adult roles as evidenced by early marriage and child labor (HRW 2014). The current child welfare system of care lacks sensitivity to these social norms, and there is a corresponding lack of responsive services for children who are pushed into adult roles. This truncated childhood experience in Malawi concurs with epidemic levels of sexual and physical VAC. In order to effectively respond, the protection of childhood is necessary and a public health continuum of care attendant for preventing VAC is described next. 


\section{Intervention Targets Based on Evidence With a Violence Prevention Framework}

Public health approaches to change include primary prevention programs oriented to stopping the problem/violence before it happens, secondary prevention programs that focus on intervening at the earliest stages of violence, and tertiary prevention programs that respond to the crisis of violence and ultimately aim for effective rehabilitation of the survivor (Centers for Disease Control and Prevention n.d.). The WHO advocates for preventing violence within family systems through programming that supports "safe, stable and nurturing relationships between children and their parents and caregivers" (WHO 2009b). These programs include parenting skills education to address "harsh parenting" (Fulu 2014) and social support interventions like home visiting programs, especially in the presence of increased risk factors (e.g., alcohol abuse and domestic violence) during infancy and early childhood (WHO 2009b).

Cultural social norms are an essential area for intervention. This includes the development of social media/marketing campaigns targeting health attitudes and beliefs that promote respect and equality (WHO 2009a). Sexual violence is an especially important target area (Ellsberg et al. 2015; Sarnquist et al. 2014). Additionally, the promulgation of appropriate laws and policies are an important aspect of social change. Effective strategies include banning corporal punishment in schools and the development of more stringent laws and policies related to sexual assault (WHO 2009a, 2009b). These approaches, targeting families, schools, and communities directly, as well as addressing the social forces underlying violence, are critical for increasing prevention and ultimately reducing mortality and morbidity related to VAC (Catalano et al. 2009; WHO, 2009a, 2009b).

\section{A Prevention Framework in Malawi: Considerations for Social Service Workforce Development}

Malawi has already developed a multisectoral approach to addressing VAC, encompassing laws, policies, programs, and services (United Nations Secretary General 2011). Now, with support from UNICEF and informed by the VACS, the government is expanding its prevention programming. As elaborated below, a policy framework along this continuum of care has been developed to structure social planning. The interventions discussed next are offered within a broad framework of the prevention continuum and focus on current programs and initiatives underway in Malawi.

\section{Tertiary Prevention: Crisis Response}

Given the endemic rate of violence, Malawian children and their families sometimes appear in medical treatment facilities for care, to interface with police, and to receive social services such as case management. In a small percentage of cases, legal/court processes are also engaged in criminal prosecution. As a result, One Stop Centers (OSCs) are undergoing rapid development as a total care approach to provide these multiple interventions in a single setting (e.g., medical and psychosocial assessment, counseling, case management, etc.). OSCs constitute a service integration model that is typically engaged in crisis situations for survivors of violence (Keesbury 2012).

With the support of UNICEF, the United Nations Population Fund, and the government of Malawi, Seventeen OSCs now exist in various stages of operation and there are plans for further expansion (Ministry of Health, Ministry of Gender, Children, Disabilities and Social Welfare, Ministry of Home Affairs and Internal Security \& Ministry of Justice and Constitutional Affairs 2014). OSCs are based on four key areas of care: (a) clinical services, with medical professionals focusing on evaluation, treatment, and mental health screening; (b) psychosocial services, with social welfare professionals focusing on assessment, case planning, and case management; (c) policing, with law enforcement professionals focusing on investigation, referrals, and safety planning support; and (d) legal services, with professionals in the court system focusing on collaboration with police and social welfare and further developing safety plans and prosecuting cases.

OSCs, using an evidence-based approach to care, are showing promising results by allowing survivors to access care in a manner that is efficient and coordinated for maximum health and legal effectiveness (United Nations Entity for Gender Equality and the Empowerment of Women n.d.). Overall, outcomes indicate greater service accessibility and efficacy across the health, psychosocial, and legal services domains. As a result, OSCs have been established globally in both high- and low-resource countries (Keesbury 2012). As a service integration system, this collaborative care model helps ensure that survivors receive coordinated care attending to a range of physical and emotional needs.

A 2011 study details several different OSC models in two African countries, Kenya and Zambia, including the health care facility-based model and the community-based nongovernmental organization model (Keesbury 2012). Evaluation research indicated that programmatic effectiveness as survivors and their caregivers perceived the psychosocial support provided by OSCs to be highly effective (Keesbury 2012). Those interviewed reported that they used OSC care repeatedly, including returning for follow-ups, counseling, and support group meetings. Integrated legal assistance was also appreciated as a beneficial service. The privacy and confidentiality afforded to survivors were also identified positively in survivor satisfaction reports (Keesbury 2012). In this model, social casework is of particular importance in the immediate and long-term (aftercare) social services. This includes highly professional engagement that is only possible with trained care providers that adhere to standards of practice and ethical engagement. 
Today, in Malawi, even with government support, critical challenges to the OSC model relate to a low uptake of services, poor follow-up, and almost no attempt at early identification or referral. Adoption of the model presents some challenges and building community trust in the process is critically important. One element of trust is the visibility of OSC and the follow-up care by the social worker in a comprehensive case management role.

At this relatively early stage of OSC program development, the case management process, usually undertaken by social workers in high-resource settings, is not truly functional in Malawi due to a lower prioritization and understanding of social work relative to legal, policing, and (medical model) clinical responses. As a consequence, early identification, referral, after care, mitigation, and reintegration programming in the community are poorly understood and implemented-programming that is fundamental to a strong social service system. Therefore, while the OSC model exists, it will remain limited so long as the functions of social workers are not fully appreciated and supported. In order to move forward, there is a need for social work training, including improved social casework skills within this particular health care setting that extends into community-based aftercare.

\section{Secondary Prevention: A Mitigating Response}

Strengthening the informal sources of support, in addition to formal service providers, is the focus of secondary prevention planning in Malawi. In order to address prevention early, one crucial strategy is to build awareness about the problem of VAC. This can be done by addressing social norms and attitudes, and through education of the community regarding how to respond. The comprehensive plan in Malawi includes parents/families, peers, community service providers, and authority figures as targets for change as they are first responders to VAC. The role of the social worker in linking, informing, and activating child guardians (parents, teachers, and community members) to identify and refer at-risk and abused children to service providers is critical.

According to VACS (Ministry of Gender, Children, Disability and Social Welfare of the Republic of Malawi et al. 2014), in almost all categories of violence, more than $50 \%$ of victims disclosed information about the abuse to a peer, friend, or family member. However, they were very rarely referred for professional child protection services. Focusing on early response is particularly important because global evidence shows early treatment minimizes trauma and optimizes psychological treatment, thereby reducing long-term harm (Margolin \& Gordis 2000).

At the secondary prevention level, parents and families are critical for engagement given their informal ability to respond immediately when their child is a victim of violence. As a result, strengthening concerned parents' knowledge about VAC signs and symptoms and educating them about where to seek services is essential. Furthermore, reinforcing the abilities of caregivers to respond appropriately-such as by responding assertively when a child is a target of violence in a school or community setting-is important.

As previously touched upon as an evidence-based intervention, parenting skills education to engage parents in prosocial and supportive behavior is another strategy (Bunting 2004; WHO 2009b). Such an approach requires providing intensive psychosocial training in family life skills, often called life skills education. A variety of programs have been proven effective in teaching parents and caregivers proactive parenting strategies (Bunting 2004; Kaminski et al. 2008) and the (WHO 2009b) promotes parenting skills interventions in their prevention recommendations.

As the VACS indicated that children often tell a friend when they experience violence, peers are another important target for engagement (Cowie \& Smith 2010) at the secondary prevention level. Again, educational programming is important in developing this social support approach (WHO 2009b), beginning with identifying youth leaders in schools and communities and educating them about the signs, symptoms, and effective responses to violence. Furthermore, training youths in peer support is an important step in secondary prevention in order to encourage help-seeking behavior (Cowie \& Smith 2010). Such an approach will support youths to take steps to seek care, often a difficult but important aspect of self-care.

Competent community service providers and authority figures, including teachers, are also critical in responding to violence as they either must be prepared when referrals are made or they must be knowledgeable about where to make further referrals enabling child victims and their families to receive appropriate services. In this category of first responders, educators are crucial as they interface with children in the school environment and can recognize the signs and symptoms of violence at the earliest stages. Valuing educators as the front line of care requires that they receive appropriate training and are supported by proactive school policies to engage in effective violence response strategies. Furthermore, at this scale of intervention, policies must be developed that support other community leaders and authority figures to engage effectively as emergency responders to VAC.

One key prevention program being brought to scale in Malawi is the Childline, a child abuse hotline that is oriented to both primary and secondary prevention. Global evidence demonstrates the efficacy of this approach in providing education as well as unbiased, non-judgmental counseling and referrals to survivors of abuse, their families, and friends (Fedunina 2011). This intervention sets the stage for engagement. However, telephone support is only truly effective when executed with parallel social services. The social worker is critical in taking leadership in complimentary program planning and service provision. At this time, there is a need for the development of parallel community-based programming to support Childline, 
including follow-up casework. The role of social workers in making referrals is also an important facet of an effective system of care (Sowers \& Rowe 2006), connecting children and their families to the existent and emerging social services.

\section{Primary Prevention: Earliest Intervention}

This particular aspect of the prevention intervention - stopping VAC before it ever occurs (Bloom 2008) - represents Malawi's greatest challenge because, at this time, a comprehensive strategy of community engagement has not yet been agreed upon fully. However, the prevalence of VAC exceeds the current social services capacity and it is impossible to meet the needs of children and families even if there was an immediate scaling-up of the service system. A strategic response requires a reduction in VAC so that services do not become overwhelmed. As such, a primary prevention approach is essential in reducing the problem and responding in a proactive manner (Bloom 2008) with an emphasis on supporting community as a place that can promote healthy growth and development of children as well as a place that supports healthy family life.

Following the release of the VACS, the Malawi government, led by the social welfare workforce, will be building a strategic approach to prevention with a healthy community and family support vision. The approach will consider three fundamental pillars - promotion of protective environments, changing of social norms, and development of children's personal protection strategies. Protective environments are those that are supportive of child growth and development within the normative social patterns in a community. For example, changing boys' attitudes towards violence and actually engaging them in being protective rather than aggressive in their social interactions. And, personal protection strategies are a range of life skills, including assertiveness as well as physical defense skills.

Community-building strategies are essential to address social norms and empower individuals, families, community leaders, and others in making these and other changes at the local level throughout the country (WHO 2009a, 2009b). As such, strengthening the protective environments of the home, school, neighborhood, and the greater community are targets for intervention. Addressing social norms, such as the culture of violence, the relationship of gender and violence, and beliefs about masculinity and power, are core to any VAC initiative. Social problems such as the prevalence of corporal punishment and early marriage are specific areas for strategic intervention informed by child rights (Bilson \& Westwood 2012; HRW 2014).

Interventions include building knowledge and awareness around child rights to create a new culture of nonviolence that prioritizes child protection. Programmatic strategies include social marketing and community building to support pro-child environments in schools and other places where children and youths engage, such as youth clubs. Knowledge building around how to discipline without violence is also important. Thus, interventions advocate engagement and education of parents and teachers in alternatives to physical punishment (Bunting 2004; Fulu 2014; WHO 2009b).

For primary prevention, local engagement in the development of community-based strategies for care must include formal and informal leaders who can set an agenda for change with an emphasis on collaboration among all stakeholders, including families, youths, children, and educators (Bloom 2008; WHO 2009a, 2009b). Developing capacity at this level of intervention is multifaceted and oriented to long-term visioning and social planning. Encouraging leadership and cultivating the requisite skills of those formal and informal leaders - especially educators and politicians - in the community is essential, beginning with the development of a community-level agenda for addressing VAC (Gamble \& Weil 2008). To achieve this aim, engagement of community leaders in promoting a climate of nonviolence is vital. In addition, the development of policies that support leadership to address violence is critical to ultimately strengthening community cohesion and commitment to safety and child rights.

\section{Social Services for Violence Prevention: Four Main Areas of Engagement}

Child protection and social welfare officers, working throughout Malawi at the community and district level (Rowan 2009), are critical social service professionals in the response to VAC. However, at this time, they are largely crisis oriented and primarily focused on providing tertiary prevention responses for children experiencing extreme violence. Moreover, most currently working at the district level have little formal education in social work and this fact ultimately undermines the full implementation of a comprehensive VAC plan. In response to the need for strengthened social service system, the government of Malawi is supporting the development of revised certificate, diploma, and degree level qualifications in social work and will be enforcing minimum qualifications for employment (Department of Social Welfare in the Ministry of Gender, Children and Social Welfare 2015). This range of education and training is one example of strategic capacity building that is taking place currently in an effort to address child rights, including VAC.

To effectively support these social service agents, their work must be further defined formally in the public health model of prevention and training in this approach to care must commence. Four main areas for social work training have been identified in further developing the capacity of social workers: (1) community building, (2) early identification of VAC, (3) social casework, and (4) program development.

\section{Community Building}

The greatest challenge will be establishing the VAC agenda for community building to address violence, including developing 
social service work plans that support community development as an outreach activity. This aspect of primary prevention (Bloom 2008) is an easy area to dismiss as social workers, and other providers invest themselves in crisis response. However, community building that focuses on developing a strategic plan in each locality is critical with full engagement of leadership across the array of stakeholders, especially political leaders, law enforcement, and authority figures such as educators (Milligan 2008). Task group work is an essential activity for social planning (Gamble \& Weil 2008). Also, communication across a variety of modes is important in outreach to promote general awareness. This raises the consciousness of community members about VAC and confronts harmful social norms. Some of the areas that can be effectively addressed in this range of intervention include the development of safe passages to schools and the development of youth activities that educate children and families about self-care, including self-defense skills.

The role of the social worker in community building, according to Milligan (2008), is the development of relationships and resources while being mindful of facilitating empowerment in natural systems. The ability to collaborate, as well as encourage collaborative relationships in group and community work, is critical as partnerships are forged and residents are mobilized in locality development, planning, and action (Gamble \& Weil 2008).

\section{Early Identification of Violence}

As the VACS indicates, many children are disclosing violence but they are rarely referred to services. As secondary prevention strategies demonstrate, identifying violence at the earliest stages is critically important to minimize the impact of trauma while engaging the child and family in services as early as possible. Social workers/child protection officers are well positioned to act as effective early interventionists. Furthermore, they are key professionals in supporting parents, teachers, and other authority figures in promptly identifying VAC and making referrals to care.

One approach to this problem is promoting community wide training on identifying the signs and symptoms of violence and the impact on children. The social worker as outreach manager and educator is a classic role (Sowers \& Rowe, 20,006). Moreover, this educational intervention approach compliments corresponding services casework where each child's needs can be addressed on a case-by-case basis.

\section{Social Casework with a Strong Aftercare Approach}

Social casework is an important social service practice activity that is essential to addressing violence across the continuum of care, especially in secondary and tertiary prevention framework (Bilson \& Westwood 2012). While social casework already exists in Malawi on a small scale, there are opportunities to further strengthen and expand this practice on a national basis. A well-trained child protection officer/social worker has critical skills in the development of care plans that are comprehensive and oriented to both immediate solutions addressing the threat of harm during crisis, as well as affecting longterm change with a tailored mental health approach for each child and family (Stardt 2008).

It is important to note that effective social casework requires an after care plan that is sustainable and oriented to long-term child protection. Social workers can effectively follow-up on the child and family to make sure the home environment is supportive of the child's long-term recovery, allowing continuation of childhood. This element of the continuum is typically ignored in resource poor settings, and children are returned to unstable, impoverished home environments, while perpetrators are not rehabilitated or removed for the child's safety. However, a well-trained child protection officer/social worker has the potential to identify solutions that protect the child and maximize their opportunities for growth and development. As such, the role of social worker includes response services including case assessment, counseling, and interfacing directly with children and families within a mental health case management framework (Roberts-DeGennaro 2008; Stardt 2008).

\section{Program Development}

Planning programs and services in a response to VAC is key to change, especially when areas 1-3 are addressed effectively. As the response system becomes more effective, new and emergent programs will be necessary in the development continuum. According to Gamble and Weil (2008), the social worker must have strong program planning and promotion skills for community-based innovations. Such work requires social workers' specialized skills related to visioning, social planning, social service administration including administrative policies, and large-scale policy proposal. An orientation to programmatic outcomes and evaluation research skills are also essential in the social worker's role (Gamble \& Weil, 20,008). Social workers, as initiators of change, are well positioned to provide this aspect of social care as setting goals and intervention development are key priorities (Sowers \& Rowe 2006).

\section{Training Needs to Build an Effective Social Services Workforce}

In order to meet the needs of these areas of engagement, the following 10 social work skill areas are presented as the basic requisite abilities necessary for effectively addressing VAC.

1. Assessment focused on individuals, families, groups, and communities including forensic assessment in extreme cases for which legal intervention is needed 
2. Social casework, including setting goals, objectives, and tasks with individuals and families

3. Counseling skills focused on the problem-solving model and ecological systems

4. Practice with groups to include self-help groups, therapeutic groups, and task groups with various stakeholders, especially health care providers, law enforcement, and educators

5. Research for program evaluation with an orientation to outcomes, as well as the process of social intervention

6. Intervention/program selection based on evidence, with considerations of gender

7. Community practice to include building support for change through a variety of activities, including engagement of local leaders

8. Developing program missions, goals, and objectives for program planning

9. Administration practice to include strategic planning, supervision, and administrative policy development

10. Policy planning, including developing policy proposals and legal frameworks for care

All of these skills must be framed by professional ethics at all scales of intervention with sensitivity for gender and other differences in Malawi. Education and training initiatives, with an emphasis on higher education for skills such as program evaluation research, are essential for developing the capacity of social workers in Malawi. Finally, it is beyond the scope of this paper to further refine these ideas and match objective education and training outcomes to violence prevention interventions. However, to achieve education and training goals, this next step of setting educational priorities is necessary.

\section{Conclusion}

Across the prevention continuum of response to violence against children, a community-level shift must occur to support social service professionals. This incorporates the confrontation of damaging beliefs about gender and violence, reducing stigma regarding care-seeking behaviors, and ultimately promoting a culture of nonviolence and respect of child rights for meaningful and sustained change. To effect change, a comprehensive strategy is essential for successful violence prevention. Focusing solely on crisis intervention represents a futile attempt to respond after the situation has already developed into an emergency; it is much more effective and efficient to invest resources at the secondary and especially primary levels to minimize or prevent VAC before it happens. Furthermore, to meet the aim of responding systematically, greater collaboration among all stakeholders is essential for VAC intervention effectiveness (Anderson 2013).
In broad terms, prevention interventions have been presented and it is beyond the scope of this article to focus in on the more nuanced strategies of social care and the interface with family and community violence. As the government of Malawi and supporting organizations move forward with a systematic approach to violence, interventions and practices will be developed and refined for social workers and allied professionals. Supporting this process is critical to sustained change, and education and training is just one of the necessary mechanisms. Broad support within the society is also necessary when considering the need to address inequalities and social norms.

Social services capacity building to respond to child protection needs is taking place globally with innovative approaches to social care, including social work training and education initiatives in low-resource countries (Mónico \& Rotabi 2014). As Malawi enters into intensive and prevention-focused social planning to respond to VACS, opportunities exist for outcomes testing of interventions at all levels of society. To carry out such a vision effectively, planning must include a nationally agreed upon collaboration strategy that is resourced correctly and includes both sufficient financing and human resources to truly realize change and protect children at the family, school, and community levels. As the various initiatives unfold, social workers have the potential to take upon leadership roles at all scales of intervention, including community-based work where the greatest need exists.

Malawi is offered as a case study to explore an emerging strategic response to VAC with a social planning approach that is inclusive of various dimensions of the social ecology of violence. As member countries move forward to respond to the WHO's call to respond to violence, especially focusing on children and youth, with Malawi's rapid progress in planning, the country may prove to be a model that can inform social intervention and social work practices in low-income settings globally. These implications have yet to be seen, but effective monitoring and evaluation research will be essential to build upon the current evidence and further refine social interventions that work in Malawi and potentially elsewhere.

\section{References}

African Child Policy Forum. (2014). The African report on violence against children. https://drive.google.com/file/d/ 0B4A1y230eseYWmVKVF9XUVozRkE/view. Accessed 15 Jan 2015.

Anderson, L. (2013). Assessment of the capacity of the Ministry of Education, Science and Technology to identify, prevent and respond to violence, abuse, and exploitation and neglect and the development of specific frameworks for violence prevention for children attending primary and secondary schools in Malawi. Colchester: CORAM Children's Legal Centre.

Baatsen, P., Kok, M., Kip, E., \& Wolmarans, L. (2014). Situation analysis: as input for the development of a costed national plan of action 
for vulnerable children. Amsterdam:Royal Topical Institute: KIT Development Policy \& Practice..

Bilson, A. W., \& Westwood, J. (2012). Making social work work: improving social work for vulnerable families and children without parental care around the world. London:Every Child.

Bloom, M. (2008). Primary prevention. In C. Franklin (Ed.), Encyclopedia of social work online. New York: Oxford University.

Bulhan, H. A. (1990). Violence. Journal of Health \& Social Policy, 1(4), 63-38.

Bunting, L. (2004). Parenting programmes: the best available evidence. Child Care in Practice, 10(4), 327-343.

Catalano, R. F., Loeber, R., \& McKinney, K. C. (2009). School and community interventions to prevent serious and violent offending. Washington DC:United States Department of Justice, Office of Juvenile Justice and Delinquent Prevention.

Centers for Disease Control and Prevention. (n.d.). The socio-ecological model: a framework for prevention. http://www.cdc.gov/ violenceprevention/overview/social-ecologicalmodel.html. Accessed 2 Aug 2014.

Centers for Disease Control and Prevention. (n.d.). Child maltreatment: consequences. http://www.cdc.gov/violenceprevention/ childmaltreatment/consequences.html. Accessed 2 Aug 2014.

Cowie, H., \& Smith, P. K. (2010). Peer support as a means of improving school safety and reducing bullying and violence. In B. Doll, W. Pfohl, \& J. Yoon (Eds.), Handbook of youth prevention science (pp. 177-193). New York: Routledge.

Dahlberg, L. L., \& Krug, E. G. (2002). Violence - a global public health problem. In E. Krug, L. L. Dahlberg, J. A. Mercy, A. B. Zwi, \& R. Lorenzo (Eds.), World report on violence and health (pp. 1-56). Geneva: World Health Organization.

Department of Social Welfare in the Ministry of Gender, Children and Social Welfare (2015). National social welfare policy. Lilongwe: Government of Malawi.

Ellsberg, M., Arango, D. J., Morton, M., Floriza, G., Kiplesund, S., Contreras, M., \& Watts, C. (2015). Prevention of violence against women and girls: what does the evidence say? Lancet, 386(9977), $1555-1566$

Farrell, J. C. (1967). Beloved lady: a history of Jane Addams' ideas on reform and peace. Baltimore:Johns Hopkins University.

Fedunina, N. Y. (2011). Literature review on help-lines for children and parents. Counseling Psychology and Psychotherapy, 2, 70-90.

Fulu, E. (2014). Links between VAC \& VAW: implications for prevention. What works to prevent violence. Tyberg: South African Medical Research Council.

Gamble, D. N. \& Weil, M. O. (2008). Community practice interventions. In C. Franklin (Ed.), Encyclopedia of social work online. New York: Oxford University.

Hammond, W. R., Whitaker, D. J., Lutzker, J. R., Mercy, J., \& Chin, P. M. (2006). Setting a violence prevention agenda at the Centers for Disease Control and Prevention. Aggression and Violent Behavior, 11(2), 112-119.

Human Rights Watch (2014). "I've never experienced happiness": Child marriage in Malawi. http://www.hrw.org/node/123427. Accessed 20 Sept 2014.

Kaminski, J. W., Valle, L. A., Filene, J. H., \& Boyle, C. L. (2008). A meta-analytic review of components associated with parenting training effectiveness programs. Journal of Abnormal Child Psychology, $36,567-589$.

Keesbury, J. O.-O. (2012). A review and evaluation of multisectoral responses to services (One Stop Centers) for gender based violence in Kenya and Zambia. Nairobi:The Population Council: Nairobi and Zambia.

Krug, E. G., Dahlberg, L. L., Mercy, J. A., Zwi, A. B., \& Lozano, R. (2002). World report on violence and health. Geneva:World Health Organization.
Larkin, H., Feletti, V. J., \& Anda, R. F. (2014). Social work and adverse childhood experiences: Implications for practice and health policy. Social Work in Public Health, 29(1), 1-16.

Levine, M., \& Levine, A. (1992). Helping children: a social history. New York: Oxford University.

Makoka, D. (2014). Formative study on violence against children in Malawi. Center for Agricultural Research and Development. Unpublished report.

Margolin, G., \& Gordis, E. B. (2000). The effects of family and community violence on children. Annual Review of Psychology, 51, 445-479.

McLennen, J. (2010). Social work and family violence: theories, assessment and intervention. New York:Springer.

Merrell, K. W., Gueldner, B. A., Ross, S. W., \& Isava, D. M. (2008). How effective are school bullying intervention programs? A meta-analysis of intervention research. School Psychology Quarterly, 23(1), 26-42.

Mian, M. (2004). World report on violence and health: what it means for children and pediatricians. Journal of Pediatrics, 145(1), 14-19.

Milligan, S. E. (2008). Community building. In C. Franklin (Ed.), Encyclopedia of social work online. New York: Oxford University.

Ministry of Gender, Children, Disability and Social Welfare of the Republic of Malawi, United Nations Children's Fund, The Center for Social Research at the University of Malawi, and the Centers for Disease Control and Prevention (2014). Violence against children and young women in Malawi: findings from a national survey, 2013. Lilongwe:Government of Malawi.

Ministry of Health, Ministry of Gender, Children, Disabilities and Social Welfare, Ministry of Home Affairs and Internal Security \& Ministry of Justice and Constitutional Affairs (2014). National guidelines for provision of services for physical and sexual violence at One Stop Centres. Lilongwe:Government of Malawi.

Mónico, C. C., \& Rotabi, K. S. (2014). International aid, relief and humanitarian assistance. In C. Franklin (Ed.), Encyclopedia of social work online. New York: Oxford University.

Moss, H. B. (2013). The impact of alcohol on society: a brief overview. Social Work in Public Health, 28(3-4), 175-177.

Population Reference Bureau. (n.d.). Why population matters to Malawi's development. http://www.prb.org/Publications/Articles/ 2012/malawi-population-2012.aspx. Accessed 2 Aug 2014.

Rippe, J. M. (2011). Violence prevention and lifestyle medicine: an imperative for all health care practitioners. American Journal of Lifestyle Medicine, 5(5), 388-389.

Roberts-DeGennaro, M. (2008). Case management. In C. Franklin (Ed.), Encyclopedia of social work online. New York: Oxford University.

Rowan, D. (2009). Malawi and AIDS: examining diversity and populations at risk. In C. J. Tice, \& D. D. Long (Eds.), International social work policy and practice: practical insights and perspectives (pp. 185-207). Hoboken: John Wiley \& Sons.

Sarnquist, C.,Omondi, B., Sinclair, J., Gitau, C., Paiva, M., Mulinge, Cornfield D. N. \& Maldonado, Y. (2014). Rape prevention through empowerment of adolescent girls. Pediatrics, 133, e1226-e1232. doi: 10.1542/peds.2013-3414.

Sixty-Seventh World Health Assembly (2014). Strengthening the role of the health system in addressing violence, in particular against women and girls, and against children. World Health Assembly (pp. 16). Geneva:World Health Organization.

Sowers, K. M., \& Rowe, W. S. (2006). Social work practice and social justice: From local to global perspectives. Boston:Cengage Learning.

Stardt, M. (2008). Mental health and children. In C. Franklin (Ed.), Encyclopedia of social work online. New York: Oxford University.

United Nations Children's Fund (UNICEF) (2014). Ending violence against children: Six strategies for action. https://drive.google.com/ file/d/0B4A1y230eseYUThtempQeVNXUDg/view. Accessed 15 Jan 2015

United Nations Entity for Gender Equality and the Empowerment of Women. (n.d.). One stop centres. Virtual Knowlege Centre to End 
Violence Against Women and Girls at http://www.endvawnow.org/ en/articles/1564-one-stop-centres-osc.html. Accessed 10 Sept 2014.

United Nations Secretary General (2011). SRSG on violence against children: global progress survey on violence against children. http://srsg. violenceagainstchildren.org/sites/default/files/global_survey/ responses/malawi/unvac_survey_malawi.pdf. Accessed 23 Nov 2014.

White, H. R., \& Widom, C. S. (2003). Intimate partner violence among abused and neglected children in young adulthood: The mediating effects of early aggression, antisocial personality, hostility and alcohol problems. Aggressive Behavior, 29(4), 332-435.
Widom, C. S. (1989). Does violence beget violence? A critical examination of the literature. Psychological Bulletin, 106(1), $3-28$.

World Health Organization (2009a). Changing cultural and social norms that support violence. Geneva:World Health Organization.

World Health Organization (2009b). Preventing violence through safe, stable and nurturing relationships between children and their parents and caregivers. Geneva:World Health Organization.

World Health Organization (2015). Malawi: WHO statistical profile. Geneva:World Health Organization. 